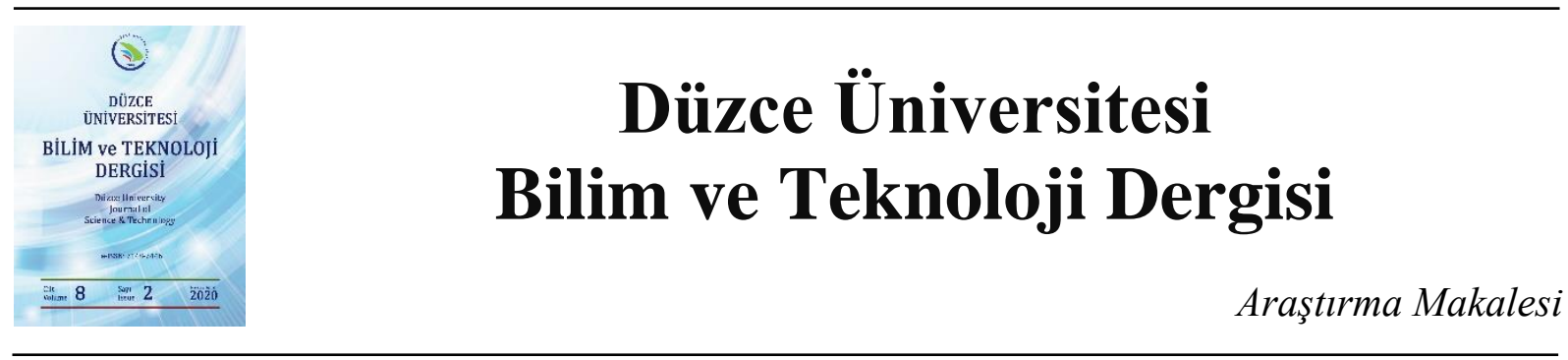

\section{Limon (Citrus limon L.) Diliminin Kurutma Sürecindeki Renk ve Boyut Analizi}

\author{
Semih ÖZDEN ${ }^{\mathrm{a}}$, (D) Faruk KILIÇ ${ }^{\mathrm{b}, *}$ \\ ${ }^{a}$ Elektronik ve Haberleşme Müh. Bölümü, Kara Harp Okulu, Milli Savunma Üniversitesi, Ankara, TÜRKIYE \\ ${ }^{b}$ Makine ve Metal Teknolojileri Bölümü, Gazi Üniversitesi, Ankara, TÜRKIYE \\ * Sorumlu yazartn e-posta adresi: farukkilic@gazi.edu.tr
}

DOI: $10.29130 /$ dubited.638632

\begin{abstract}
ÖZET
Narenciyenin özellikle de limonun tüketimi tüm dünyada oldukça yaygındır. Narenciyeyi saklamak için farklı yöntemler mevcuttur ancak içindeki nemin büyük oranda uzaklaştırarak saklama yöntemi (kurutma) yüzyıllardır süregelen bir uygulamadır. Limon dilimlerinin kurutulması ve kurutulmasının incelenmesi (uygun sıcaklık ve nem kapasitesinin belirlenmesi) akademik olarak da araştırılan konuların başında gelmektedir. Yapılan bu çalışmada, çakışık merkezli fan-rezistans ile kontrol edilen gıda kurutma firınında $50{ }^{\circ} \mathrm{C}$ 'de kurutulan limon dilimlerinin zamana bağlı olarak görüntü kaydı ve kinematik özelliklerinden ağırlığın (nem kaybının) ölçümü yük hücresi ile gerçekleștirilmiștir. Verilerin ve parametrelerin güvenirliliği arttırmak için üçer defa tekrarlanan deneyler, Türk Standartları Enstitüsü'nün TS 13706 kurutulmuş limon standardına uygun olarak (kurutulmuş limonda \% 10 nem kalıncaya dek) gerçekleştirilmiştir. Toplamda 330 dakika süren kurutma sürecinde, firın içine yerleştirilen sayısal kamera ile 30 dakikalık aralıklarla görüntü kaydedilmiştir. Yapılan deneyler sonucunda elde edilen verilere göre normalize ağılık kaybı \% 75.8 olarak kaydedilmiştir. Limon dilimi görüntüleri kenar belirleme algoritmaları ile işlenerek piksel sayısı belirlenmiș ve \% 19.42 azalma gösterdiği ölçülmüștür. RGB verileri sayısal kameradan elde edilerek MATLAB programı ile analiz edilmiştir. Renkte oluşan değişim değerlendirildiğinde fark \% 13.78 olarak tespit edilmiştir. Böylece limon dilimlerin renginin ve alanının değişimi ortaya çıkartılmıştır. Bu matematiksel değişimler (renk, alan, ağırlık) arasında karmaşık ağ yapıları ile matematiksel olarak bağlantı kurularak, kurutma sürecinin yönetimi, kontrolü sağlanabilir.
\end{abstract}

Anahtar Kelimeler: Gıda kurutma, Limon dilimi, Görüntü işleme, Boyut analizi, Renk analizi

\section{Color and Size Analysis of Lemon Slice (Citrus lemon L.) during Drying Process}

\begin{abstract}
The consumption of citrus, especially lemon, is very common all over the world. There are different methods for storing citrus, but the method of storing (drying) by removing the moisture is a centuries-old practice. Drying of lemon slices and drying process (determining the appropriate temperature and humidity capacity) are among the topics that are researched academically. In this study, the measurement of the weight (moisture loss) of the lemon slices, which were dried at $50^{\circ} \mathrm{C}$ in a food drying oven controlled by a coincident-centered fan-resistance, was carried out with the load cell depending on the time. In order to increase the reliability of the data and parameters, the experiments repeated three times were carried out in accordance with the TS 13706 dried lemon standard of the Turkish Standards Institute (until 10\% moisture is left in the dried lemon). During the drying process, which lasted 330 minutes in total, the image was recorded at 30-minute intervals with the digital camera placed inside
\end{abstract}


the oven. According to the data obtained as a result of the experiments, normalized weight loss was recorded as 75.8\%. Lemon slice images were processed with edge detection algorithms and the number of pixels was determined and it was measured to show a $19.42 \%$ decrease. RGB data were obtained from digital camera and analyzed with MATLAB program. When the change in color was evaluated, the difference was determined as $13.78 \%$. Thus, the change of the color and area of the lemon slices are revealed. The management and control of the drying process can be achieved by mathematically connecting complex network structures between these mathematical changes (color, area, weight) with MATLAB program. When the change in color was evaluated, the difference was found to be $13.78 \%$.

Keywords: Food drying, Lemon slice, Image processing, Dimension analysis, Color analysis

\section{GIRIS}

2017 Birleşmiş Milletler Gida ve Tarım Organizasyonu (FAO) verilerine göre Dünyada 1084505 hektar alana ekili olan limondan 17218173 ton ürün alındığı belirtilmektedir. Bu verilere göre 158765 hektogram / hektar verim elde edildiği görülmektedir [1]. Asya, Amerika, Afrika ve Avrupa kıtalarına bakılacak olursa en fazla ekili alanın 502079 hektar ile Asya kıtasında, en az ekili alan ise 74232 hektar ile Avrupa kıtasında olduğu gözlenmiştir. Aynı kıtaların verimleri incelenecek olursa en yüksek verim 189911 hektogram / hektar ile Avrupa kitasinda, en az verim ise 135435 hektogram / hektar ile Afrika kıtasında elde edildiği anlaşılmaktadır. Hindistan Brezilya, Çin, İspanya, Meksika ve ABD dünyanın narenciye meyvelerinin üçte ikisini üretmektedir [2]. Asya kıtasında üretimin daha fazla olması sebebi ile daha az üretim yapılan bölgelere ihracatının önemi büyüktür. Bu sebeple sulu narenciyenin nakliye maliyetlerinin düşürülmesi amacıyla kurutulmuş gıda üretimi ön plana çıkmıştır.

Kurutma gıda bünyesindeki su oranının \%75-95 oranlarından \%10-20 oranlarına renk, besin değeri, görünüş, bozulma ömrü gibi kalite özelliklerini oldukça az değiş̧irerek azaltılmasıdır [3]. Binlerce yıldır insanoğlu, kuru gıda eldesi için güneş radyasyonundan faydalandı. Geleneksel kurutma yönteminde, kurutma hızı birkaç dış faktör (güneş radyasyonu, ortam sıcaklığı, rüzgâr hızı ve bağıl nem) ve iç faktör (ilk nem içeriği, ürün tipi ve ürün kütlesi) tarafından kontrol edilmektedir [4].

Büzülme, renk ve rehidrasyon kapasitesi kurutulmuş gıdada kalitenin göstergesi olarak kullanılır. Gıdanın nem kaybına bağlı olarak hacmi azalır, aynı zamanda da yüzey alanı küçülür. Bu da kurutma işlemini, rehidrasyon kabiliyetini, dokusunu ve ürün kalitesini önemli oranda etkiler [5-6].

García-Pérez ve ark. akustik enerjinin limon kabuğunu kurutmadaki etkileri üzerine çalışmalar yapmıştır [7]. Chen ve ark. kapalı tip güneş kurutucusu kullanarak limon dilimleri üzerindeki kurutma etkisini incelemiş̧ir [8]. Sonuçta kapalı tip bir güneş kurutucu kullanan kurutulmuş limon dilimlerinin duyusal parametreler açısından daha iyi genel kalite seviyelerine sahip olduğunu göstermektedir. Sadeghi ve ark. konvektif, mikrodalga ve birleşik mikrodalganın limon dilimlerinin kurutulması sırasında kütle transfer özellikleri üzerine çalışmalar yapmıştır [9]. Wang ve ark. kızılötesi radyasyonla 1sıtılan darbeli vakumlu kurutucu kullanarak farklı kurutma sicaklıklarının $\left(60^{\circ} \mathrm{C}, 65^{\circ} \mathrm{C}, 70^{\circ} \mathrm{C}\right.$ ve $\left.75{ }^{\circ} \mathrm{C}\right)$ limon dilimlerinin kuruma özellikleri, büzülme, rehidrasyon kinetiği, mikro yapı ve renk profilleri üzerindeki etkisini incelemiş̧ir [10]. Limon kurutma işleminin $60^{\circ} \mathrm{C}$ den $75^{\circ} \mathrm{C}$ ye çıkarıldığında kurutma süresinin $10.5^{\prime}$ ten 5.5 saate düştügünü gözlemlemiştir. Ancak $75^{\circ} \mathrm{C}$ lik sıcaklık limon dilimlerinde önemli ölçüde renk değişimi gözlenmiştir. Torki-Harchegani ve ark. firında kurutulan limon dilimlerinin dehidrasyon özellikleri ve matematiksel modelinin elde edilmesi hakkında çalışmalar yapmıştır [11]. Gıda kurutma konusunda sayısal modelleme ile daha birçok çalışma yapılmıştır [12-13]. Daha önce birçok yazar makalelerinde farklı türlerdeki narenciye kabuğu özlerinin antioksidan içeriğini rapor etmiştir. En uygun kurutma modelinin Midilli ve Küçük modeli olduğu gözlemlendi. Etkili nem yayılımı Fick'in ikinci yasasına göre belirlenmiş ve $1.62^{\times} 10^{-11}, 3.25^{\times} 10^{-11}$ ve $8.11^{\times} 10^{-11}$ olarak elde edilmiştir. 50,60 ve $75^{\circ} \mathrm{C}$ kurutma sıcaklıkları için ortalama konvektif kütle aktarım katsayısının sırasıyla $5.71^{\times} 10^{-7}, 1.62^{\times} 10^{-6}$ ve $2.53^{\times} 10^{-6} \mathrm{~ms}^{-1}$ olduğu hesaplanmıştır. [14-16]. 
Kurutma ve görüntü analizi birçok çalışmada ele alınmıştır. Jokic ve arkadaşları'nın gerçekleştirdiği çalışmada, sıcak hava kurutmalı bir firında önişlem yapılmış elma dilimlerinin renk analizi yapılmış ve kurutma sürecinin optimizasyonu gerçekleştirilmiştir. Farklı kimyasal önişlem ve sıcaklık altında RGB ve CIE Lab değerleri elde edilerek Page's eşitliği ile modelleme yapılmıştır [17]. Bir başka elma çalışmasında, vakum fırını üç farklı sıcaklık değerinde sabit tutularak nem oranı ve renk değişiminin (RGB) analizi gerçekleştirilmiştir. Her 30 dakikada bir kayıt alınarak gerçekleştirilen kurutma sürecinde doğrusal bir model ortaya konulmuştur [18]. Onwude ve arkadaşları tarafından görüntü işleme (RGB ve $\mathrm{Lab}$ ) ve lazer tabanlı geri-yayılımlı görüntü analizi teknikleri birleştirilerek patates dilimlerinin kurutma sürecindeki öznitelik kalitelerinin tayini için kullanılması amaçlanmıştır. Farklı kurutma sıcaklık değerleri kullanıldığı çalışmada geliştirilen model ile sıcaklık ve kurutma zamanının ilişkisi ortaya konulmuş ve \%70'in üzerinde bir R2 değeri elde edilmiştir [19].

Bu çalışmada, limon dilimlerinin renk değişiminin kurutma işlemi esnasında analizi yapılmış ve nem kaybı ile ilişkisi incelenmiştir. Kurutma firınının iç sıcaklığı ve nemi, kurutma süresince sabit tutularak limon dilimlerinin nem kaybı bir başka deyişle ağırlığın değişimi geliştirilen elektronik sistem ile kaydedilmiş̧ir. Farklı görüntüleme sistemleri kullanılmasına karşın sayısal kameranın kullanıldığı sistemler basit, düşük maliyetli ve hızlıdır. Ayrıca görüntüden elde edilen veriler çok çeşitli uygulamalar için iyi sınıflandırma performansı gösterir [20]. Bu sebeplerden dolayı bu çalışmada da, sayısal kamera ile limon dilimlerinin görüntüsü alınmıştır. Deney sonucunda limon dilimlerinin RGB olarak renk değişimi analiz edilmiştir. MATLAB ortamında geliştirilen yazılım ile birlikte deney sonunda kurutma süresince renk, piksel ve ağırlık değişimi elde edilmiştir. Böylece, kurutma sürecinde limon dilimlerinin renk ve piksel açısından nasıl değiştiği gözlenmiştir. Bu da sonraki çalışmalar için bir yol gösterici olacaktır.

\section{MATERYAL ve METOT}

\section{A. GIDA KURUTMA FIRINI (GKF) ve KURUTMA SÜRECI}

Kurutma deneyleri, seri kontrollü çakışık merkezli fan-rezistans ikilisi ile çalışan firında paslanmaz çelik 316 sac tepside yapılmıştır (Şekil 1). Gıdanın kurutma süreci, fırın içindeki nemi ve sıcaklığı ayarlanarak kontrol sağlanmıştır. Olası süre aşımlarını önlemek amacı ile GKF'nin süre kontrolü zaman rölesi ile sağlanmıştır. Ortam sıcaklığı, fan-motor ikilisini eş zamanlı olarak çalışmasını kontrol eden termostat ile sağlanmıştır. Ortamdaki nemin dışarı atılması firın üzerindeki deliklerle sağlanmış olup deneysel olarak kanıtlandıktan sonra deneye başlanmıştır. Ortam sıcaklığı ve nemi, geliştirilen mikroişlemci tabanlı bir sistem ile bilgisayar ortamına aktarılarak kaydedilmiştir.

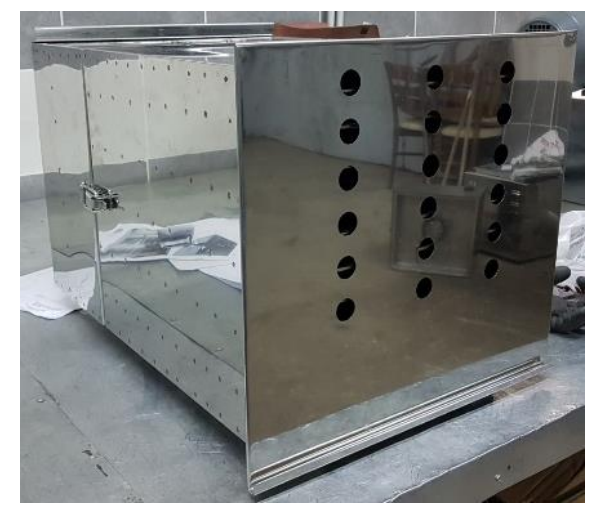

Şekil 1. Glda kurutma firinı

Fırın içi sıcaklığın ve nemin yanı sıra gıdanın kaybetmiş olduğu ağırlığı tespit edebilmek amacı ile yük hücresi eklenmiştir. Yük hücresi kurutmanın sağlandığı tepsinin altına monte edilmiştir. Sıcaklık için Termokupl kullanılmıştır. Ortamdaki fiziksel büyüklüklerin ölçülmesinde kullanılan algılayıcılara ait 
parametreler ve özellikler Tablo 1'de sunulmuştur. Sistemde mikroişlemci olarak Arduino UNO tercih edilmiş olup algılayıcılardan gelen verilen analog kanallardan okunmuştur. USB bağlantısı üzerinden bilgisayara kaydedilerek analiz ve yorumlamalar gerçekleştirilmiştir.

Tablo 1. Gıda kurutma firınında kullanılan cihaz özellikleri

\begin{tabular}{lll}
\hline Kullanılan Cihaz & Özellikleri & Ölçüm Aralı̆̆ı \\
\hline Sıcaklık ölçer & Sicaklık ölçümü & $-20^{\circ} \mathrm{C} \sim 85^{\circ} \mathrm{C}$ \\
\hline Yük hücresi & A ğırlık kapasitesi & En fazla $1 \mathrm{~kg}$ \\
\hline Zaman rölesi & Ortam / depolama sıcaklığı & $0 \ldots 50^{\circ} \mathrm{C} /-25 \ldots 70^{\circ} \mathrm{C}$ \\
\hline
\end{tabular}

Deneylerde Mersin kaynaklı, Sınıf I, orta boy limon kullanılmıştır. Citrus limon (L.) Burm. $f$. türüne giren ve TS 34'e uygun nitelikteki taze limonların, varsa meme kısımları kesildikten sonra uzunluk eksenine dikey olacak şekilde, halka şeklinde dilimlenerek usulüne uygun olarak kurutulmuştur [21]. Limon dilim kalınlıkları ayarlanabilen Zyliss marka dilimleme makinesinde 3mm dilimlendikten sonra kurutulmuştur (Şekil 2). Ölçümün güvenirliği için, kurutma deneyi üç defa tekrarlanmıştır.

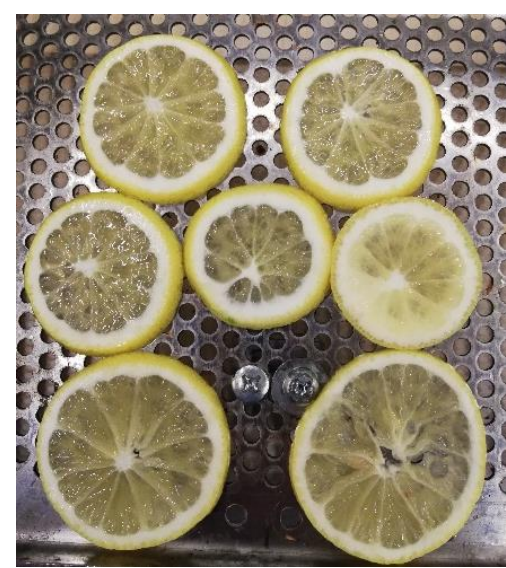

(a)

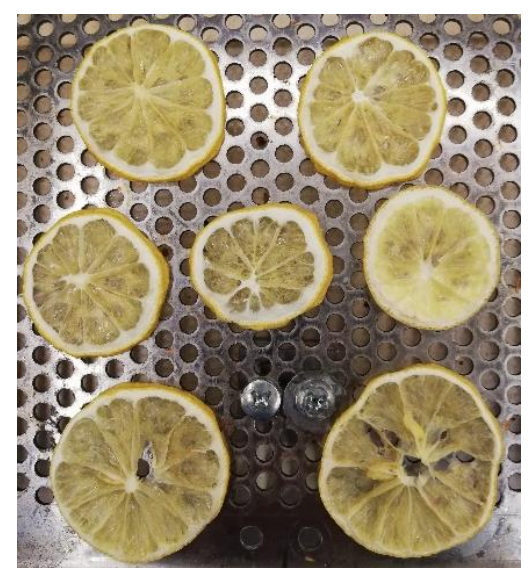

(b)

Şekil 2. a) Limon dilimi b) Kuru limon dilimi

TS 13706 kodlu standart gereği kuru gidada \% 10 nem olması gerekmektedir [21]. Kuru kütle belirlemek için yapılan deney art arda iki ölçüm sonucu arasında ağılıkça \% 1' den daha az fark oluşuncaya dek devam ettirilmiştir [22-23]. Yapılan kurutma deneylerinde dilimlenmiş limon ağırlığındaki fark \% 1 den daha az olduğu tespit edilince kurutma işlemine son verilmiştir.

\section{B. GÖRÜNTÜ ANALİŻ}

Görüntü / video işleme son dönemde üzerinde çok fazla çalışan ve endüstriyel kontrol alanlarına uygulanabilen veya uygulama potansiyeli araştırılan bir konudur. Çeşitli özelliklere sahip kameralardan elde edilen görüntüler sayesinde farklı analiz yöntemleri kullanılarak bir çıkarım yapmak mümkündür. Görüntünün işlenerek hedeflenen çıkarımların gerçekleştirilmesi bir dizi kodlama ile gerçekleştirilmektedir. Kodlamada kullanılan farklı algoritmalar her geçen gün farklılaşmakta, çeşitlenmekte ve karar verici sistemin doğruluğunu arttırmaktadır. Gıda sektöründe de görüntü işleme gıdaların özellikle kalite kontrolünde kullanılmakta ve ürün kalitesini arttırmaktadır [24-25]. Gıdaların kurutma açısından bakıldığında, kurutma süresince kurutulan gıdanın şekil ve renk açısından değişikliklere uğradığı gözle görülmektedir [26-27].

Bu çalışmada, limon dilimlerinin kurutma süresince otuz dakika aralıkla görüntüsü alınarak boyut ve renk analizi yapılmıştır. Literatürdeki renk analiz çalışmalarında farklı renk gösterim metotları kullanılmıştır. Bunlardan bazıları RGB (Kırmızı, Yeşil, Mavi), $L^{*} a * b$ (parlaklık, kırmızılık/yeşillik, 
mavilik/sarılık), HSL (renk, doyum, 1şık) ve HSV (renk, doyum, değer) olarak gösterilebilir. Bu çalışmada, sayısal kameradan sağlanan görüntülerin RGB olarak elde edilen verileri MATLAB programı kullanılarak analiz edilmiştir. Analizde her bir renk değerindeki değişimin karelerinin toplamının karekökü renk farkı $\left(\Delta E_{R G B}\right)$ Eşitlik 1 kullanılarak hesaplanmıştır.

$\Delta E_{R G B}=\sqrt{\left(R_{k}-R_{t}\right)^{2}+\left(G_{k}-G_{t}\right)^{2}+\left(B_{k}-B_{t}\right)^{2}}$

Burada, $k$ indisi kurutma anındaki rengi, $t$ ise kurutma önceki (taze) renk değerini göstermektedir. Limon dilimlerinin görüntülerinden kenar belirleme algoritmaları kullanılarak işlenecek pikseller belirlenmiştir ve bu belirlenen pikseller sayılarak limon dilimlerinin kurutma süresince oluşan alan kaybı hesaplanmıştır.

\section{ARASTIRMA SONUCLARI ve TARTISMA}

Dilimlenmiş limon için yapılan deneylerde yatay eksende süre dakika biriminde, dikey eksende ise ağırlık gram biriminde verilmiştir (Şekil 3). Grafik dilimlenmiş limonun barındırdığı suyun buharlaşması sebebiyle azalan bir yol izlemiştir. $50^{\circ} \mathrm{C}$ de kurutulan dilimlenmiş limon deneyi $( \pm 5 \mathrm{dk}$.) 330 dakika sürmüştür. Deneyler esnasında 1sıtıcı ve fan yardımı ile fırın içi bağıl nemi \%1 de tutulmuştur.

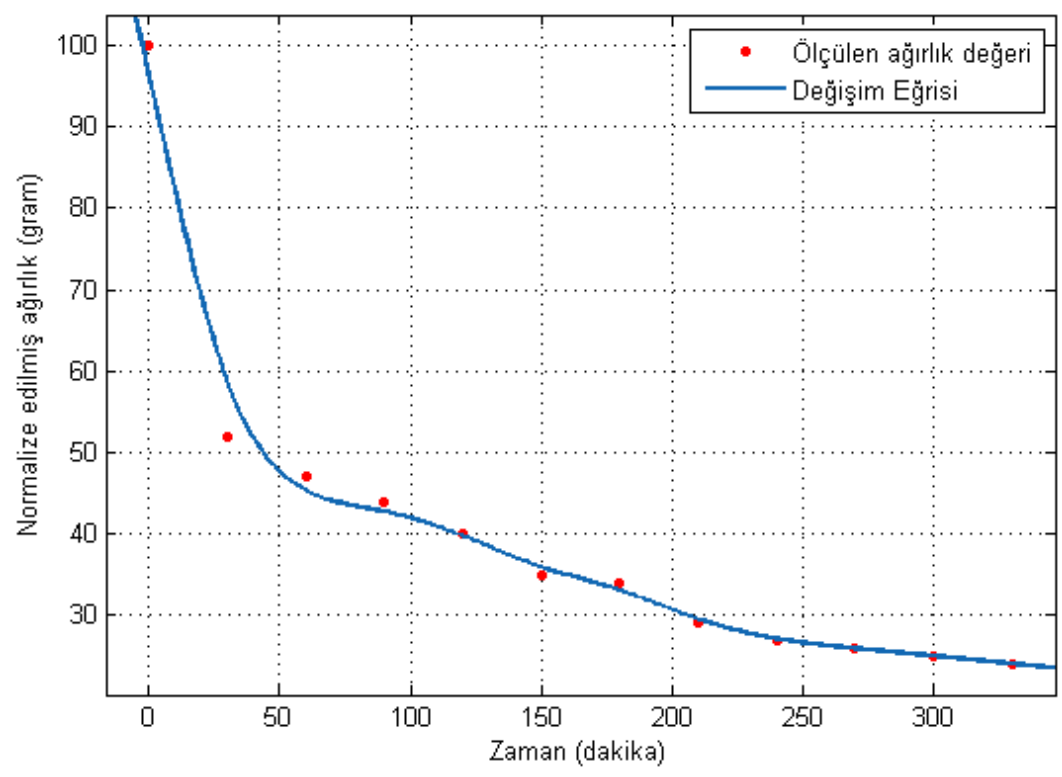

Şekil 3. Zamana bağlı normalize edilmiş ă̆ırlık grafiği

Kenar belirleme algoritmaları ile limon dilimlerinin sınırları belirlenmiş ve bu sınırlı alanda kalan piksellerin sayısı hesaplanmıştır. Kurutma süresince piksel sayısındaki değişim Şekil 4'te gösterilmiştir. Kırmızı nokta ile işaretlenen değerler otuz dakikalık aralıklarla alınan görüntüdeki piksel sayısını (y ekseni) ve $\mathrm{x}$ ekseni ise dakika cinsinden süreyi göstermektedir. Bu verilerin eğri uydurma yöntemleri ile çizilen grafik şekil üzerinde görülmektedir. 


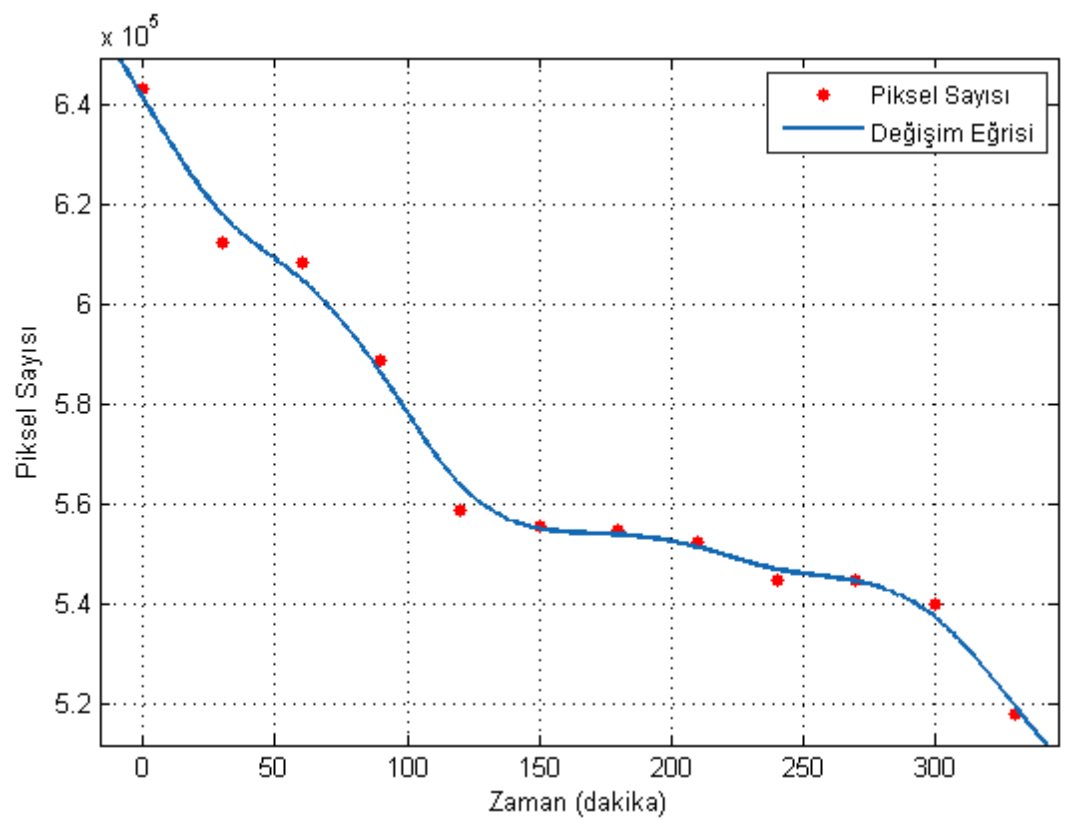

Şekil 4. Zamana băgll piksel sayısl grafiği

Eşitlik 1'de verilen matematiksel ifade kullanılarak kenarı belirlenmiş limon diliminin her bir pikseli için oluşan renk farkı hesaplanmış ve değişimi Şekil 5'te sunulmuştur.

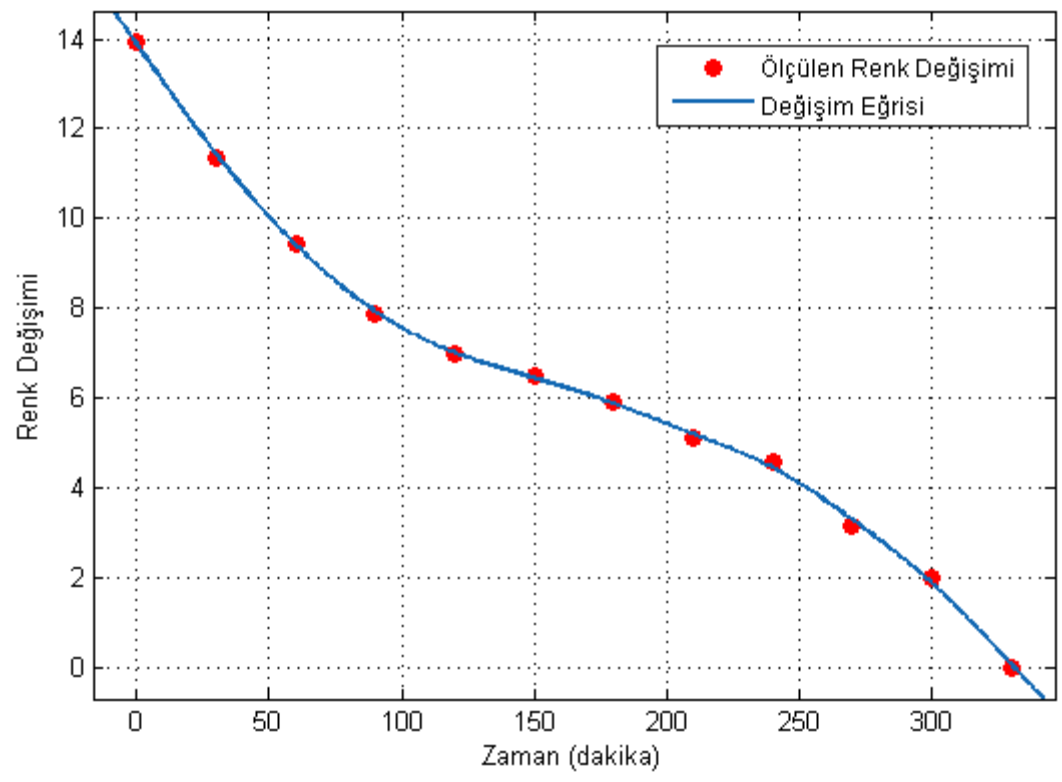

Şekil 5. Zamana bağll renk değişimi grafiği

Toplamda 330 dakikalık kurutma süresince elde edilen verilere göre limon dilimlerinin ağırlık kaybı, renk değişimi ve piksel sayısı ilk saatlerde hızlı bir değişim göstermiş. Sonraki süreçte su kaybı yavaşlarken piksel sayısı ve renk değişimi yavaşlamadan sonra kurutmanın bitişine doğru tekrar hızlandığı gözlenmiştir. Literatürde yer alan çalışmalar, genellikle kurutma kinetiğinin incelenmesi üzerinedir ve görüntü işleme ile yapılan çalışma azdır, limon ile alakalı olarak bulunamamıştır. $\mathrm{Bu}$ makalenin amacı, kurutma sürecindeki değişimleri gözlemlemek, ileri seviyede yapılacak çalışmalara (renk değişimi, farklı ortam ve sıcaklıklarda uygulamalar) örnek teşkil etmektir. Bunun yanı sıra limon dilimlerinin kurutma sürecindeki tepkisi ve nem atma dinamiği de elde edilmiştir. 


\section{IV.SONUC}

Yapılan bu çalışmada, $3 \mathrm{~mm}$ kalınlıktaki limon dilimlerinin $50^{\circ} \mathrm{C}$ 'de kurutulmuştur. Kurutma süresince, ağırlığın zamana bağlı olarak değişimi algılayıcılar ile tespit edilmiş ve kurutma sonunda \% 75.8 'lik bir değişim olduğu tespit edilmiştir. Piksel sayısında oluşan değişimin \%19.42, bir başka deyişle limon dilim alanı kaybının bu oranda olduğu belirlenmiştir. Renkte meydana gelen değişime bakıldığında farkın \%13.78 olduğu görülmüsştür. Bu sayısal değişimler limon dilimlerinin kurutulmasında kullanılan harici bir algılayıcıya ihtiyaç kalmadan kurutma sürecinin kameradan elde edilen görüntüler ile birlikte yönetilebileceğini göstermektedir. Bundan sonraki çalışmalarda elde edilen verilerle ilgileşim (korelasyon) analizleri yapılarak aralarındaki bağlantı ve ilişki daha detaylı olarak incelenebilir. Bunun yanında farklı kalınlık, sıcaklık, çap, 1sıtma kaynağı gibi deneyler ile modelleme yapılabilir.

\section{KAYNAKLAR}

[1] Anonymous. (2018, May 24). The State of Food Security and Nutrition in the World [Online]. Available: http://www.fao.org/faostat/en/\#data/QC.

[2] G. Paggiola, S. V. Stempvoort, J. Bustamante, J. M. V. Barbero, A. J. Hunt and J. H. Clark, "Can bio-based chemicals meet demand? Global and regional case-study around citrus waste-derived limonene as a solvent for cleaning applications. " Biofuels, Bioproducts and Biorefining, vol. 10, no. 6, pp. 686-698, 2016.

[3] F. Kılıç ve A. Köse, "Meyve-sebze kurutma makineleri için arduino tabanlı neme duyarlı fan kontrol tasarımı," 1st International Turkish World Engineering and Science Congress, Antalya, Türkiye, 2017, pp. 176-180.

[4] D. Jain and G. N. Tiwari, "Thermal aspects of open sun drying of various crops," Energy, vol. 28 , pp. 37-54, 2003.

[5] B. K. Koua, P. M. E. Koffi and P. Gbaha, "Evolution of shrinkage, real density, porosity, heat and mass transfer coefficients during indirect solar drying of cocoa beans," Journal of the Saudi Society of Agricultural Sciences, vol. 18, pp. 72-82, 2019.

[6] L. A. Ramallo and R. H. Mascheroni, "Quality evaluation of pineapple fruit during drying process," Food and Bioproducts Processing, vol. 90, pp. 275-283, 2012.

[7] J. V. García-Pérez, J. A. Cárcel, E. Riera and A. Mulet, "Influence of the Applied Acoustic Energy on the Drying of Carrots and Lemon Peel," Drying Technology, vol. 27, pp. 281-287, 2009.

[8] H.-H. Chen, C. E. Hernandez and T.-C. Huang, "A study of the drying effect on lemon slices using a closed-type solar dryer," Solar Energy, vol. 78, pp. 97-103, 2005.

[9] M. Sadeghi, O. Mirzabeigi Kesbi and S. A. Mireei, "Mass transfer characteristics during convective, microwave and combined microwave-convective drying of lemon slices," Journal of the Science of Food and Agriculture, vol. 93, pp. 471-478, 2013.

[10] J. Wang, C.-L. Law, P. K. Nema, J.-H. Zhao, Z.-L. Liu, L.-Z. Deng et al., "Pulsed vacuum drying enhances drying kinetics and quality of lemon slices," Journal of Food Engineering, vol. 224, pp. 129$138,2018$. 
[11] M. Torki-Harchegani, M. Ghasemi-Varnamkhasti, D. Ghanbarian, M. Sadeghi and M. Tohidi, "Dehydration characteristics and mathematical modelling of lemon slices drying undergoing oven treatment," Heat and Mass Transfer, vol. 52, pp. 281-289, 2016.

[12] I. Dincer, "Moisture loss from wood products during drying - part 1: moisture diffusivities and moisture transfer coefficients," Energy Sources, vol. 20, pp. 67-75, 1998.

[13] I. Dincer and S. Dost, "Determination of moisture diffusivities and moisture transfer coefficients for wooden slabs subject to drying," Wood Science and Technology, vol. 30, pp. 245-251, 1996.

[14] A. Delpino-Rius, J. Eras, F. Vilaró, M. Á. Cubero, M. Balcells and R. Canela-Garayoa, "Characterisation of phenolic compounds in processed fibres from the juice industry," Food Chemistry, vol. 172, pp. 575-584, 2015.

[15] S. Lagha-Benamrouche and K. Madani, "Phenolic contents and antioxidant activity of orange varieties (Citrus sinensis L. and Citrus aurantium L.) cultivated in Algeria: Peels and leaves," Industrial Crops and Products, vol. 50, pp. 723-730, 2013.

[16] B. B. Li, B. Smith and M. M. Hossain, "Extraction of phenolics from citrus peels: I. Solvent extraction method," Separation and Purification Technology, vol. 48, pp. 182-188, 2006.

[17] S. Jokic, J. Lukinac, D. Velic, M. Bilic, D. Magric and M. Planinic. (2020, May 20). Optimization of drying parametersand color changes of pretreated organic apple slices [Online]. Available: https://pdfs.semanticscholar.org/fb5c/cd1241836d093c7f5d19904801016ddc855a.pdf.

[18] G. C. Bora, R. Pathak, M. Ahmadi, and P. Mistry, "Image processing analysis to track colour changes on apple and correlate to moisture content in drying stages," Food Quality and Safety, vol. 2, pp. 105-110,2018.

[19] D. I. Onwude, N. Hashim, K. Abdan, R. Janius and G. N. Chen, "Combination of computer vision and backscattering imaging for predicting the moisture content and colour changes of sweet potato (Ipomoea batatas L.) during drying," Computers and Electronics in Agriculture, vol. 150, pp. 178-187, 2018.

[20] K. Vijayarekha, "Machine vision application for food quality: A review," Research Journal of Applied Sciences, Engineering and Technology, vol. 4, pp. 5453-5458, 2012.

[21] Kurutulmuş Elma- Özellikler ve Deney Metotları, Türk Standartlar Enstitüsü TS 3688, 2009.

[22] W. Horwitz, "Official methods of analysis of the association of official analytical chemists," Arlington, Virginia, 1990, c. 17, s. 1-2.

[23] H. İ. Variyenli, M. B. Özdemir, M. G. Özkaya, F. Kılıç and H. Kaçmaz, "Comparison performance of flat surface drying owen with performances performance of absorber surface," Gazi Journal of Engineering Science, vol. 1, pp. 305-324, 2015.

[24] T. Brosnan and D. W. Sun, "Improving quality inspection of food products by computer vision - a review," Journal of Food Engineering, vol. 61, pp. 3-16, 2004.

[25] D. Mery and F. Pedreschi, "Segmentation of colour food images using a robust algorithm," Journal of Food Engineering, vol. 66, pp. 353-360, 2005. 
[26] L. Fernandez, C. Castillero and J. M. Aguilera, "An application of image analysis to dehydration of apple discs," Journal of Food Engineering, vol. 67, pp. 185-193, 2005.

[27] A. Yadollahinia and M. Jahangiri, "Shrinkage of potato slice during drying," Journal of Food Engineering, vol. 94, pp. 52-58, 2009. 